\title{
Formation and properties of composite nanostructured PEO- coatings on metals and alloys
}

\author{
Dmitry V. Mashtalyar ${ }^{1,2, *}$, Igor M. Imshinetsky ${ }^{1}$, and Sergey L. Sinebryukhov ${ }^{1}$ \\ ${ }^{1}$ Institute of Chemistry Far Eastern Branch of Russian Academy of Sciences, 690022 Vladivostok, 159 100-letiya Vladivostoka Pr., \\ Russia \\ ${ }^{2}$ Far Eastern Federal University, 690950 Vladivostok, 8 Sukhanova St., Russia
}

\begin{abstract}
Results of investigation of the incorporation of zirconia and titanium nitride nanoparticles into the coatings formed on magnesium alloy by plasma electrolytic oxidation are presented. Comprehensive research of electrochemical and mechanical properties of obtained coatings was carried out. It was established that the polarization resistance of the samples with a coating containing zirconia nanoparticles is in two fold higher than for the sample with base PEO-coating. One of the important reasons for improving the protective properties of coatings formed in electrolytes containing nanoparticles consists in enhanced morphological characteristics, in particular, the porosity decrease and increase of thickness and resistivity of porousless sublayer in comparison with base PEO-layer. Incorporation of zirconia and titanium nitride particles into the coating increases the mechanical performances. The coating containing nanoparticles have greater hardness and are more wear resistant in comparison with the coatings formed in the electrolyte without nanoparticle.
\end{abstract}

\section{Introduction}

Magnesium and its alloys have been used widely in various fields of engineering, such as aircraft, electronic, automobile owing to the combination of low density, high strength to weight ratio, higher damping capacity and high machinability. However, high corrosion activity and low wear resistance of magnesium alloys significantly have limited their applications. A proper surface treatment may improve wear and corrosion resistance of the substrate. There are some surface treatment techniques established for protection of magnesium and its alloys. These techniques include chemical conversion plating, anodizing, gas-phase deposition, electrodeposition, organic coatings and solgel technique.

Plasma electrolytic oxidation (PEO), also called micro-arc oxidation (MAO), is an economic, efficient, and environmentally friendly technology capable of producing a stable oxide coating on the surface of light metals (Al, Mg, Ti, Zr, Ta, etc.) or alloys [1,2]. The oxide coatings have controllable morphology and composition, excellent adhesion to substrate, good electrical and thermal properties, high microhardness, wearproof and corrosion resistance. The PEO formation is induced by micro-discharges on the metal surface and accompanied by gas evolution. Various processes, including chemical, electrochemical, thermodynamic, and plasma-chemical reactions occur at the discharge sites, due to increased local temperature $\left(10^{3}\right.$ to $\left.10^{4} \mathrm{~K}\right)$ and pressure $\left(\approx 10^{2} \mathrm{MPa}\right)$. These processes are responsible for modifying the structure, composition, and morphology of obtained oxide coatings. Coatings formed by the PEO process usually contain crystalline and amorphous phases with constituent species originating from both the metal and electrolyte. Recent developments in this area are focused on the addition of nanoparticles into the electrolyte, aiming at in-situ incorporation them into PEO-coatings [3-15]. The corrosion resistance was effectively improved by the addition of $\mathrm{TiO}_{2}$ nanoparticles in the electrolyte [5]. An increased coating strength has been shown for PEOcoatings formed in electrolytes with powders of $\mathrm{Al}_{2} \mathrm{O}_{3}$, $\mathrm{TiO}_{2}, \mathrm{Cr}_{2} \mathrm{O}_{3}, \mathrm{ZrO}_{2}, \mathrm{TiC}, \mathrm{B}_{4} \mathrm{C}, \mathrm{BN}$ [9]. Suspensions of $\mathrm{Al}_{2} \mathrm{O}_{3}$ [16] have been employed to produce coatings with enhanced thermomechanical properties, reduced surface porosity and increased wear-resistance.

The main aim of the present study is to investigate the influence of the incorporation of nanoparticles zirconia $\left(\mathrm{ZrO}_{2}\right)$ and titanium nitride (TiN) into the coatings via PEO process in the phosphate-based electrolyte in the relationship with their structural and corrosion performances and mechanical properties.

\section{Methods}

Rectangular plates with size of $15 \mathrm{~mm} \times 20 \mathrm{~mm} \times 2 \mathrm{~mm}$ made of the magnesium alloy MA8 (1.5 wt. \% Mn; 0.15 wt. \% Ce; $\mathrm{Mg}$ - balance) were used as samples. Prior to oxidation, for the surface standardization, the samples underwent mechanical treatment by grinding paper of

\footnotetext{
* Corresponding author: madiva@inbox.ru
} 
different grain sizes $(600,800$, and 1200), washed with distilled water, and degreased by ethanol.

Two different kind of nanomaterials were used as additive, namely zirconia with particle size of up to 100 $\mathrm{nm}$ and titanium nitride with particle size of $20 \mathrm{~nm}$. Three different electrolytes consisting of $5.0 \mathrm{~g} / 1 \mathrm{NaF}$, $15.0 \mathrm{~g} / 1 \mathrm{Na}_{2} \mathrm{SiO}_{3}$ termed as bath $\mathrm{A}$, which was then modified by adding $3 \mathrm{~g} / 1 \mathrm{ZrO}_{2}$ termed as bath $\mathrm{B}$ or $3 \mathrm{~g} / \mathrm{l}$ TiN termed as bath C. Since at the plasma electrolytic oxidation the coating growth proceeds, as a rule, at the anodic polarization of treated sample, to ensure the maximal embedding of particles into the coating, an anionic surfactant was used as a stabilizer of the disperse system. The process of coatings formation was carried out using a plasma electrolytic oxidation apparatus. A conventional reversive thyristor rectifier was used as a power supply. The frequency of polarizing pulses was $300 \mathrm{~Hz}$; the duty cycle was $50 \%$. All the samples were treated in the two-stage bipolar PEO-mode. At the first stage, the anodic component was set galvanostatically at a current density of $0.5 \mathrm{~A} / \mathrm{cm}^{2}$; the cathodic phase was set potentiostatically at $-30 \mathrm{~V}$. The duration of the first PEO-stage was $200 \mathrm{~s}$ : here, the anodic voltage attained $300 \mathrm{~V}$. During the second stage, within $600 \mathrm{~s}$ the anodic component was changed potentiodynamically from 300 to $200 \mathrm{~V}$, whereas the cathodic one - from -30 to $-10 \mathrm{~V}$.

The element composition of surface layers was determined using the energy dispersive X-ray fluorescence analysis (EDXRF) on an EDX-800HS spectrometer (Shimadzu, Japan).

Electrochemical properties of the obtained layers have been investigated with the use a VersaSTAT MC electrochemical system (Princeton Applied Research, USA). The studies have been carried out in the threeelectrode cell at room temperature in a $3 \% \mathrm{NaCl}$ solution. A platinum mesh has been used as a counter electrode. The saturated calomel electrode (SCE) was used as a reference electrode. The surface area of the sample exposed to the electrolyte was equal to $1 \mathrm{~cm}^{2}$.

Studies of mechanical properties, in particular, determination of microhardness and elasticity modulus of the coatings material were carried out using a DUHW201 Dynamic Ultramicrohardness Tester (Shimadzu, Japan). Measurements of the universal microhardness were carried out on a cross-section using a Vickers indenter at a load of $50 \mathrm{mN}$.

Adhesion properties of surface layers were studied by scratch test on a Revetest (CSM Instruments, Switzerland). Experiments were carried out at a preset trace length of $5 \mathrm{~mm}$ chosen empirically and a gradual load increase from 1 to $20 \mathrm{~N}$ at a rate of $9.5 \mathrm{~N} / \mathrm{min}$. For scratch testing, a Rockwell diamond indenter with an angle of $120^{\circ}$ and a tip radius of $200 \mu \mathrm{m}$ was used. The study was carried out by measuring the friction force and the friction coefficient, recording the acoustic emission, and fixing critical loads, at which characteristic destruction traces emerged. For each type of coating, the following parameters were determined: the load at which the first cracking occurs, $L_{c_{1}}$; the load at which the extent of fracture events increases, $L_{\mathrm{C}_{2}}$; loads, at which coating scratching down to metal occurred, $L_{\mathrm{C}_{3}}$.
Tribological tests were performed using a Tribometer (CSM Instruments, Switzerland) in accordance with the 'ball-on-plate' scheme. A ball of a diameter of $10 \mathrm{~mm}$ made of alumina was used as a counterbody. All the studies were carried out under dry friction and ambient conditions $\left(25^{\circ} \mathrm{C}\right.$ and relative humidity of $\left.50 \%\right)$. A normal load was equal to $10 \mathrm{~N}$. The linear rotation speed was equal to $50 \mathrm{~mm} / \mathrm{s}$, the track diameter was equal to 10 $\mathrm{mm}$. The coatings wear, I, was calculated using the normalization of the sample volume loss during tests $\Delta V_{\text {samp }}$ on the values of run $(N)$ and applied load $(P)$ : $I=\Delta V_{\text {samp }} /(N P)$. The sample volume loss is as follows: $\Delta V$ samp $=S \cdot l$, where $l$ is the trace length and $S$ is the area of cross section of the wear trace.

\section{Results and discussions}

According to the data obtained using scanning electron microscopy (Fig. 1), the morphology of surface layers obtained in baths A, B and C differs substantially. The surface of the coating containing zirconia nanoparticles (Fig. 1(b)) is smoother in comparison with the convolute surface of the coating obtained in the base electrolyte without nanoparticles (Fig. 1(a)) and in the titanium nitride-containing electrolyte (Fig. 1(c)). The porosity of coating fabricated in the base electrolyte is equal to 5.0 $\%$. This parameter for PEO-layers formed in baths B and $\mathrm{C}$ was equal to 2.2 and $4.1 \%$, respectively. The porosity of the coatings containing nanoparticles is lower due to partial sealing of the pores. In case of using nanosized particles of titanium nitride, the surface possesses the highest roughness parameter $(R a=2.0 \mu \mathrm{m})$ as compared to the base PEO-coating $(R a=1.23 \mu \mathrm{m})$ and PEO-layer with $\mathrm{ZrO}_{2}$ nanoparticles $(R a=1.21 \mu \mathrm{m})$.

The element composition of coatings was determined by EDXRF analysis (Table 1). The incorporation of nanoparticles in the coating is nearly equal for both zirconia and titanium nitride. The concentration of zirconium and titanium attained 1.7 and $1.8 \mathrm{wt} . \%$ for coatings formed respectively in bath $\mathrm{B}$ and $\mathrm{C}$. It was found that most of the nanosized particles are concentrated in the surface layer of PEO-coating.

To evaluate the corrosion resistance of the obtained coatings, their electrochemical properties were investigated. Analysis of polarization curves (Fig. 2) enable one to conclude on a substantial positive effect of nanosized zirconia and titanium nitride in the composition of the forming electrolyte on anticorrosion properties of the fabricated coatings. Corrosion currents density $\left(I_{c}\right)$ of the samples with coatings formed in in baths $\mathrm{B}$ are significantly lower in comparison with the sample with base PEO-layer (Table 2). One of the important reasons for improving the protective properties of coatings formed in baths $\mathrm{B}$ is the enhancement of morphological characteristics, in particular blocking the micropores and cracks, giving rise to a denser coating, which acts as an effective barrier to suppress corrosion. Corrosion current density for coatings containing TiN nanoparticles increased in 1.5 fold in comparison with coatings obtained without the nanopowder (Table 2). The deterioration of the protective properties of the 
coatings containing TiN nanoparticles is mainly explained by high conductivity of titanium nitride. Besides, the coatings obtained using nanoparticles contain chemical compounds $\left(\mathrm{ZrO}_{2}\right.$, TiN) having much higher chemical stability as compared to that of the main components of the base PEO-layer.

Table 1. EDXRF results of the sample treated by PEO in baths A, B and C.

\begin{tabular}{|l|c|c|c|c|c|c|c|c|}
\hline Sample & $\begin{array}{c}\text { Mg } \\
\text { (wt.\%) }\end{array}$ & $\begin{array}{c}\mathbf{O} \\
\text { (wt.\%) }\end{array}$ & $\begin{array}{c}\mathbf{S i} \\
\text { (wt.\%) }\end{array}$ & $\begin{array}{c}\mathbf{Z r} \\
\text { (wt.\%) }\end{array}$ & $\begin{array}{c}\text { Ti } \\
\text { (wt.\%) }\end{array}$ & $\begin{array}{c}\text { Na } \\
\text { (wt.\%) }\end{array}$ & $\begin{array}{c}\text { Mn } \\
\text { (wt.\%) }\end{array}$ & $\begin{array}{c}\text { Others } \\
\text { (wt.\%) }\end{array}$ \\
\hline Bath A & 37.8 & 38.4 & 18.5 & - & - & 1.2 & 3.0 & 1.1 \\
\hline Bath B & 36.6 & 36.6 & 19.1 & 1.7 & - & 1.9 & 3.5 & 0.6 \\
\hline Bath C & 40.1 & 38.0 & 15.3 & - & 1.8 & 2.6 & 1.7 & 0.5 \\
\hline
\end{tabular}
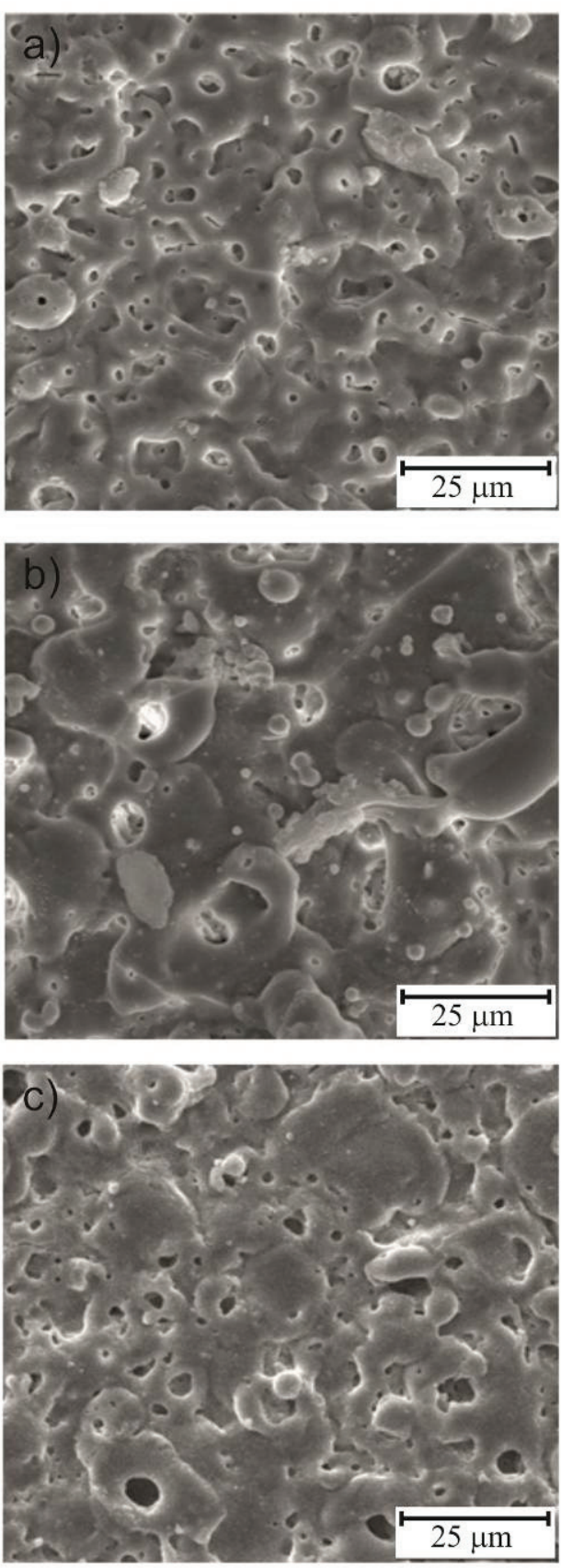

Fig. 1. SEM images of the surface of PEO coatings formed in the different electrolytes: (a) bath A, (b) bath B and (c) bath C.

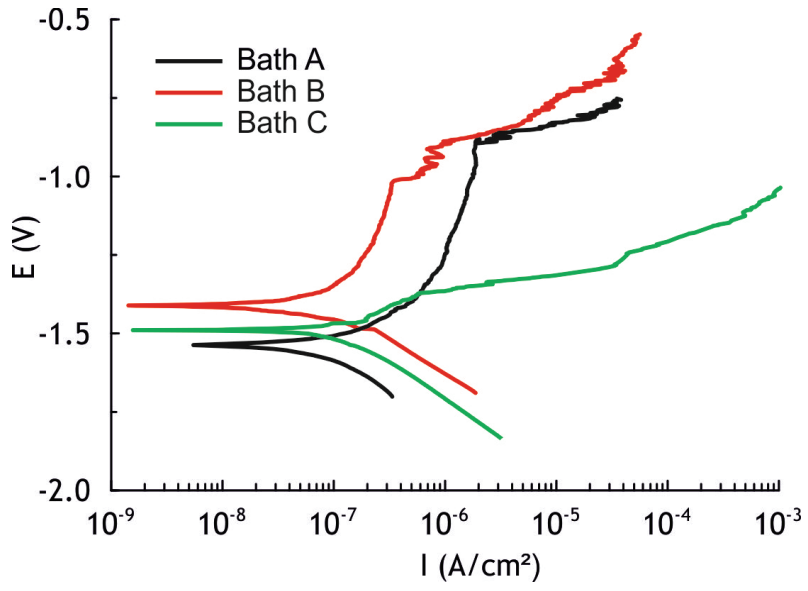

Fig. 2. Potentiodynamic polarization curves of the samples treated by $\mathrm{PEO}$ using baths $\mathrm{A}, \mathrm{B}$, and C

Table 2. Corrosion performances of MA8 magnesium alloy samples.

\begin{tabular}{|l|c|c|c|}
\hline Sample & $\begin{array}{c}\boldsymbol{R}_{\mathbf{p}} \\
\left(\mathbf{\Omega} \cdot \mathbf{c m}^{\mathbf{2}}\right)\end{array}$ & $\begin{array}{c}\boldsymbol{I}_{\mathbf{c}} \\
\left(\mathbf{A} / \mathbf{c m}^{\mathbf{2}}\right)\end{array}$ & $\begin{array}{c}\boldsymbol{E}_{\mathrm{c}} \\
(\mathbf{V} \text { vs. } \mathbf{S C E})\end{array}$ \\
\hline Bath A & $2.8 \times 10^{5}$ & $1.2 \times 10^{-7}$ & -1.45 \\
\hline Bath B & $6.1 \times 10^{5}$ & $5.3 \times 10^{-8}$ & -1.42 \\
\hline Bath C & $1.7 \times 10^{5}$ & $1.8 \cdot 10^{-7}$ & -1.47 \\
\hline
\end{tabular}

Evaluation of the mechanical properties of the fabricated coatings was carried out using the method of microhardness testing. Obtained results (Table 3) testified, that the layers containing nanoparticles are harder in comparison with the coatings formed in bath $\mathrm{A}$ $\left(H_{\mu}=2.1 \pm 0.3 \mathrm{GPa}\right)$. The coating containing TiN nanoparticles possesses the highest microhardness $(4.2 \pm 0.5) \mathrm{GPa} . \mathrm{ZrO}_{2}$ nanoparticles provide somewhat lower microhardness value, $(3.7 \pm 0.8) \mathrm{GPa}$. Such increase is, probably, related to the composition and properties of the embedded nanoparticles and the surface layer morphology.

Table 3. Microhardness and Young's modulus for the magnesium alloy MA8.

\begin{tabular}{|l|c|c|}
\hline Sample & $\begin{array}{c}\text { Microhardness } \\
(\mathbf{G P a})\end{array}$ & $\begin{array}{c}\text { Young's modulus } \\
(\mathbf{G P a})\end{array}$ \\
\hline Bath A & $2.1 \pm 0.3$ & $60 \pm 5$ \\
\hline Bath B & $3.7 \pm 0,8$ & $97 \pm 12$ \\
\hline Bath C & $4.2 \pm 0.5$ & $98 \pm 10$ \\
\hline
\end{tabular}

Adhesion of coating to substrate was evaluated using the scratch test. To determine the coating material 
elastoplastic properties, the repeated registration of the indenter trace profile was carried out after unload. The value of the load corresponding to the first cracks $\left(L_{\mathrm{C} 1}\right)$ for all types of the studied coatings is equal to $5.0 \pm 0.3 \mathrm{~N}$. The load, at which the coating is worn down to metal $\left(L_{\mathrm{C} 3}\right)$, varies from 14.3 to $20.4 \mathrm{~N}$ for the coatings under study (Table 4).

Table 4. Mechanical characteristics of coatings determined by scratch test.

\begin{tabular}{|c|c|c|c|}
\hline Sample & $\begin{array}{l}L_{\mathrm{C} 1} \\
(\mathrm{~N})\end{array}$ & $\begin{array}{l}L_{\mathrm{C} 2} \\
(\mathrm{~N})\end{array}$ & $\begin{array}{l}L_{\mathrm{C} 3} \\
(\mathrm{~N})\end{array}$ \\
\hline Bath A & \multirow{3}{*}{$5.0 \pm 0.3$} & $8.4 \pm 0.5$ & $13.8 \pm 0.2$ \\
\hline Bath B & & $9.4 \pm 0.7$ & $14.3 \pm 0.7$ \\
\hline Bath C & & $10.5 \pm 0.9$ & $20.4 \pm 1.9$ \\
\hline
\end{tabular}

Tribological tests were performed to evaluate wearproof of samples under study. Fig. 3 shows the dependencies of the friction coefficient $\mu$ on the number of cycles. Tests were carried out until the coating wear down to metal. In general, the trend to positive effect of embedded nanomaterials into the coatings composition on their mechanical properties is preserved (Fig. 3, Table 5). Wear of coatings containing nanoparticles is lower than for the samples without additives. Due to higher microhardness and lower porosity the coatings with $\mathrm{ZrO}_{2}$ and TiN nanoparticles withstand a 1.4-1.9 fold more number of load cycles, as compared to the base PEO-layer. One should mention that the slope angle of the curve of friction coefficient for the coatings obtained in electrolytes with nanoparticles is smaller than that for the base PEO coating. This fact is related to differences in the morphology and chemical composition of the coatings under study.

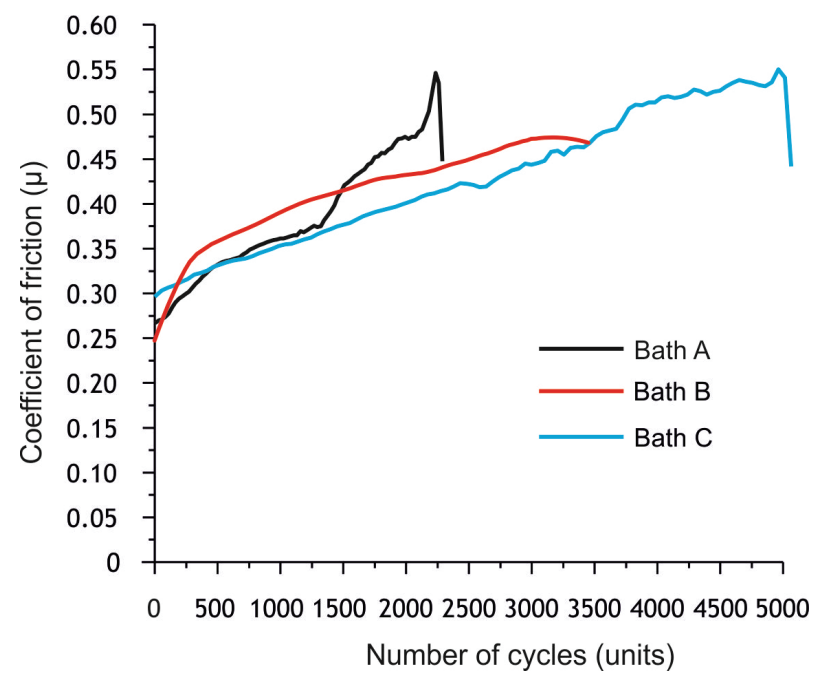

Fig. 3. Dependence of the friction coefficient of the corundum ball/sample on number of cycles for samples treated by PEO using baths $\mathrm{A}, \mathrm{B}$, and $\mathrm{C}$.

Table 5. Wear of coatings.

\begin{tabular}{|l|c|c|}
\hline Sample & $\begin{array}{c}\text { Wear rate } \\
\left(\mathbf{m m}^{\mathbf{3}} / \mathbf{( N \cdot \mathbf { m } )}\right)\end{array}$ & Cycles \\
\hline Bath A & $(4.1 \pm 0.4) \times 10^{-5}$ & 2560 \\
\hline Bath B & $(2.9 \pm 0.2) \times 10^{-5}$ & 3540 \\
\hline Bath C & $(1.9 \pm 0.1) \times 10^{-5}$ & 4865 \\
\hline
\end{tabular}

\section{Conclusion}

The incorporation of $\mathrm{ZrO}_{2}$ and TiN nanoparticles into the coating via PEO of magnesium alloy MA8 was successfully achieved. As a result, the corrosion protection and mechanical properties of the coatings were improved considerably. Embedded nanoparticles modify the morphological structure, for instance, the porosity is decreased. The insertion of nanoparticles into the coating composition increases the microhardness and wear resistance in almost 2 fold as compared to the PEOcoating without nanoparticles.

This work was supported by the Russian Science Foundation (№ 14-33-00009).

\section{References}

1. Q. Li, J. Liang, Q. Wang, Modern Surface Engineering Treatments, 75-99 (2013)

2. F. Walsh, C. Low, R. Wood, K. Stevens, J. Archer, A. Poeton, A. Ryder, Trans. Inst. Met. Finish. 87, 122-135 (2009)

3. X. Lu, M. Mohedano, C. Blawert, E. Matykina, R. Arrabal, K. Kainer, M. Zheludkevich, Surf. Coat. Technol. 307, 1165-1182 (2016)

4. X. Li, B. Luan, Mater. Lett. 86, 88-91 (2012)

5. Y. Song, X. Sun, Y. Liu, Mater. Corros. 63, 813818 (2012)

6. R. Bhuyan, T. Kumar, D. Goswami, A. James, A. Perumal, D. Pamu, Mater. Sci. Eng., B 178, 471476 (2013)

7. S.V. Gnedenkov, S.L. Sinebryukhov, D.V. Mashtalyar, I.M. Imshinetskiy, A.V. Samokhin, Yu.V. Tsvetkov, J. Nanomater. 2015, 1-12 (2015)

8. D.V. Mashtalyar, S.V. Gnedenkov, S.L. Sinebryukhov, I.M. Imshinetskiy, A.V. Puz', J. Mater. Sci. Technol. 33, 461-468 (2017)

9. V. Malyshev, K. Zorin, Appl. Surf. Sci. 254, 15111516 (2007)

10. Y. Wang, D. Wei, J. Yu, S. Di, J. Mater. Sci. Technol. 30, 984-990 (2014)

11. M. Daroonparvar, M.A.M. Yajid, N.M. Yusof, H.R. Bakhsheshi-Rad J. Alloys Compd. 688, 841-857 (2016)

12. S.V. Gnedenkov, S.L. Sinebryukhov, D.V. Mashtalyar, I.M. Imshinetskiy, A.V. Samokhin, Yu.V. Tsvetkov, Vacuum. 120, 107-114 (2015)

13. C.-J. Hu, M.-H. Hsieh, Surf. Coat. Technol., 258, 275-283 (2014)

14. S.V. Gnedenkov, S.L. Sinebryukhov, I.A. Tkachenko, D.V. Mashtalyar, A.Y. Ustinov, A.V. Samokhin, Y.V. Tsvetkov, Inorg. Mater. Appl. Res., 3, 151-156 (2012)

15. M. Shokouhfar, S.R. Allahkaram, Surf. Coat. Technol. 291, 396-405 (2016)

16. Y. Khokhryakov, P. Butyagin, A. Mamaev, J. Mater. Sci. Lett. 40, 3007-3008 (2005) 